\title{
Adição de finos de rocha granítica e seus efeitos nas propriedades de argamassas autoadensáveis
}

\author{
Granite rock fines addition and its effects on self- \\ compacting mortars' properties
}

\begin{abstract}
Thaís Pinto Lôbo Siqueira
José da Silva Andrade Neto

Cleber Marcos Ribeiro Dias

Daniel Veras Ribeiro

\section{Resumo}

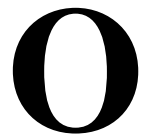

presente estudo avalia a utilização de finos de rocha granítica (FRG)

em argamassas autoadensáveis, visando obter características reológicas adequadas sem incorporar aditivos modificadores de viscosidade. Para isso, realizaram-se ensaios de minifunil- $\mathrm{V}$ e minislump test e ensaios de caracterização físico-mecânica em argamassas de referência (sem FRG) e com teores de substituição de FRG iguais a 5\%, 15\% e $25 \%$ em relação ao volume de cimento. Avaliou-se a hidratação das pastas que compõem essas argamassas, por meio da técnica de calorimetria isotérmica. Posteriormente, foi analisada a porosidade teórica das pastas, por meio do ensaio de compacidade, visando obter o espaçamento entre partículas (IPS) das pastas. Ao incorporar FRG, a viscosidade da argamassa foi ajustada, com o aumento do tempo de escoamento em até $4,3 \mathrm{~s}$, reduzindo-se o consumo de cimento em até $12 \%$ e, consequentemente, a liberação de calor durante a hidratação. Ademais, concluiu-se que a incorporação de FRG reduz a porosidade das argamassas em até $17,63 \%$ e aumenta a resistência à compressão em cerca de $11 \%$ como consequência da adição de $15 \%$ de FRG. No entanto, pelo fato de reduzir a distância entre as partículas da pasta, aumentou-se o consumo de teor de aditivo superplastificante para alcançar o espalhamento ideal.
\end{abstract}

Palavras-chave: Argamassa autoadensável. Finos de rocha granítica. Reologia. Calor de hidratação. Propriedades mecânicas.

${ }^{1}$ Thaís Pinto Lôbo Siqueira ${ }^{1}$ Universidade Federal da Bahia Salvador - BA - Brasil

${ }^{2}$ José da Silva Andrade Neto 2Universidade Federal da Bahia Salvador - BA - Brasil

${ }^{3}$ Cleber Marcos Ribeiro Dias ${ }^{3}$ Universidade Federal da Bahia Salvador - BA - Brasil

${ }^{4}$ Daniel Véras Ribeiro ${ }^{4}$ Universidade Federal da Bahia Salvador - BA - Brasil

Recebido em 01/09/19 Aceito em 22/04/20

\section{Abstract}

The present study evaluates the use of granite rock fines (GRF) in self-compacting mortars, aiming to obtain adequate rheological characteristics without incorporating viscosity modifying additives. For this, mini Funnel-V, mini Slump Test and physical-mechanical characterization tests were carried out on reference mortars (without GRF) and with GRF substitution levels equal to 5\%, 15\% and $25 \%$, to cement's volume. The hydration of the pastes of these mortars was also evaluated using the isothermal calorimetry technique. Subsequently, the theoretical porosity of the pastes was analyzed through the compactness test, in order to obtain the interparticle spacing (IPS) of these pastes. When incorporating $G R F$, the viscosity of the mortar was adjusted, increasing the flow time by up to 4.3 sec, reducing cement consumption by up to $12 \%$ and, consequently, the release of heat during hydration. Furthermore, it was concluded that the incorporation of GRF reduces the porosity of mortars by up to $17.63 \%$ and increases the compressive strength by about $11 \%$ as a result of the addition of $15 \%$ FRG.

However, due to the fact that the distance between the particles of the paste is reduced, the consumption of superplasticizer additive content has been increased to achieve the ideal spreading.

Keywords: Self-compacting mortar. Granitic rock fines. Rheology. Heat of hydration. Mechanical properties. 


\section{Introdução}

A argamassa autoadensável, parte constituinte do concreto autoadensável responsável pela trabalhabilidade, possui a capacidade de se autoadensar em função da ação da gravidade, sem necessitar de energia externa de compactação. Para isso, esse material precisade alta fluidez e resistência à segregação, sendo essas propriedades resultado da utilização de aditivos superplastificantes e/ou modificadores de viscosidade e da incorporação de finos. A incorporação dos aditivos e dos finos faz com que o custo final da argamassa autoadensável seja expressivamente superior ao custo das argamassas tradicionais, sendo, assim, uma barreira na disseminação dessa tecnologia. Contudo, a aplicação de misturas autoadensáveisnas construções fornece diversas vantagens, tais como melhor acabamento superficial, elevada rapidez na execução e maior liberdade arquitetônica, pois possui maior facilidade de alcançar locais de difícil acesso por não necessitar de adensamento e de nivelamento (BENLI; KARATAS; BAKIR, 2017; ABDOLLAHNEJAD et al., 2017; SAHMARAN; CHRISTIANTO; YAMAN, 2006).

Nesse cenário, o fino de rocha granítica, resíduo do processo de britagem, surge como possível solução para a redução do consumo de aditivos, de forma a adequar as propriedades reológicas das argamassas autoadensáveis. O FRG possui reduzido valor agregado e é, normalmente, disposto de maneira inadequada nos pátios das pedreiras, acarretando diversos impactos ambientais, além de estar relacionado a diversas doenças respiratórias, como silicose e câncer de pulmão (RODRIGUES; MANTOVANI; LOPES, 2004; ALMEIDA; SAMPAIO, 2002; FELEKOGLU, 2007; D’AGOSTINO; SOARES, 2003).

Diversos autores estudaram a influência da incorporação de finos de rocha granítica provenientes da fabricação de agregado graúdo ou do beneficiamento de rochas artesanais em concretos e argamassas. Alguns desses estudos mostram que a incorporação de FRG afeta a reologia das misturas, com tendência de adicionar-se mais aditivo superplastificante, devido a sua elevada finura, além de se obter maior tempo de escoamento, indicando possível acréscimo da viscosidade das matrizes (LI et al., 2019; SADEK; ELATTAR; ALI, 2016; HO et al., 2002). A incorporação de finos pode, também, aumentar a resistência à segregação e a habilidade passante das misturas e, assim, resultar em matrizes mais homogêneas. Isso se dá pelo aumento da viscosidade das formulações, que acabam por garantir melhor distribuição de agregados no interior da mistura e auxiliar na passagem das formulações por barreiras físicas como as armaduras (SADEK; EL-ATTAR; ALI, 2016; ELYAMANY; ELMOATY; MOHAMED, 2014).

Além disso, a incorporação de materiais finos como FRG tende a melhorar o desempenho mecânico e reduzir a absorção de água das misturas, devido à densificação da matriz proveniente do eficiente preenchimento de poros que a adição desse material promove (SADEK; EL-ATTAR; ALI, 2016; ELMOATY, 2013; ELYAMANY; ELMOATY; MOHAMED, 2014). Com a redução da quantidade de poros permeáveis, a incorporação de FRG pode resultar em matrizes mais duráveis, uma vez que a entrada dos agentes agressivos se dá, majoritariamente, através dos poros.

Assim, o emprego desse resíduo nas matrizes apresenta possibilidade de agregar valor econômico aos finos de rocha, além de minimizar o impacto ambiental causado pela ineficiente disposição final desse resíduo. Além disso, estudos apontam que a adição de FRG pode reduzir consideravelmente o teor de aditivos utilizado, acarretando a redução do custo final do empreendimento e tornando o concreto e a argamassa autoadensáveis mais competitivos comercialmente (FELEKOGLU, 2007; HO et al.,2002). A redução do consumo de aditivo diminui também o impacto ambiental gerado pelo elevado consumo de aditivo químico normalmente empregado em argamassas autoadensáveis sem finos.

A análise teórica da distância de separação das partículas, interparticle separation distance (IPS), da pasta constituinte das argamassas pode auxiliar no desenvolvimento dessas argamassas autoadensáveis. Esse estudo se baseia na análise da porosidade proveniente da distribuição granulométrica da mistura dos materiais utilizados na pasta, FRG e cimento, nas diferentes proporções empregadas. Quanto maior for a porosidade resultante da mistura dos materiais empregados, maior será a quantidade de líquido necessário para iniciar o afastamento dos grãos (CARDOSO, 2009; DAMINELI, 2013; FUNK; DINGER, 1994).

Isso se deve ao fato de que, quando o teor de fluido presente na dosagem é inferior ou equivalente à porosidade total da mistura, essa não irá fluir, uma vez que as partículas estarão em contato direto entre si. Sendo assim, somente quando a quantidade de fluido adicionado na mistura for suficiente para preencher todos os espaços vazios e recobrir por completo a superfície de todas as partículas, terá início o processo de escoamento da mistura (MACIEL et al., 2018; CARDOSO, 2009).

A distância de separação das partículas está diretamente relacionada à trabalhabilidade das argamassas autoadensáveis, em que a fluidez da mistura aumenta com maior distância de separação de suas partículas. 
Em contrapartida, em misturas em que as partículas estão muito próximas ocorre uma perda da fluidez. Essa análise teórica permite maior embasamento quando da avaliação do teor de aditivo superplastificante necessário para alcançar o mesmo espalhamento (CARDOSO, 2009; DAMINELI, 2013). Estudos mostram que, quanto menor o valor encontrado para o IPS, maior a dificuldade para iniciar-se o escoamento das misturas, aumentando simultaneamente a tensão de escoamento e a viscosidade do material. Isso se deve ao fato de que, com a redução do IPS, as partículas dos finos que compõem a pasta tendem a colidir de forma mais acentuada umas com as outras, gerando aumento significativo do atrito existente entre as partículas, o que, consequentemente, aumenta a viscosidade plástica das misturas (DAMINELI, 2013; ROJASRAMÍREZ et al., 2019; VARHEN et al., 2016).

Estudos que avaliem a influência da incorporação desses finos, em diferentes teores, na dosagem de argamassas autoadensáveis ainda são escassos e apresentam conclusões divergentes. Assim sendo, este estudo visa avaliar a influência da adição de FRG nas propriedades das argamassas autoadensáveis tanto no estado fresco quanto no endurecido, além de analisar a influência dessa adição no distanciamento das partículas que constituem as pastas das argamassas analisadas.

Dessa maneira, o objetivo do presente trabalho é avaliar a viabilidade da utilização de finos de rocha granítica em argamassas autoadensáveis, de maneira a adequar a viscosidade dessas, evitando, assim, a utilização de aditivos modificadores de viscosidade. Para isso, o resíduo foi determinado e pastas e argamassas contendo diferentes teores do resíduo foram caracterizadas por meio de ensaios de calorimetria, minifunil-V, mini-slump test, e ensaios de caracterização físico-mecânica no estado endurecido.

\section{Materiais e métodos}

Para a moldagem das argamassas autoadensáveis, foi utilizado o cimento CP II-F-32, fornecido pela InterCement, por ser o cimento mais usado na região de Salvador e que não possui adições minerais que pudessem mascarar os resultados.

Os finos de rocha granítica foram gerados e fornecidos em uma pedreira localizada na região metropolitana de Salvador, Bahia; aareia natural é proveniente de jazidas da região de Camaçari, Bahia; e o aditivo superplastificante à base de policarboxilato, Hyperkem 80, é da empresa Novakem. O FRG foi peneirado mecanicamente, de forma a utilizar apenas a fração do material com partículas de dimensão inferior a 75 $\mu \mathrm{m}$, o que correspondeu a cerca de $74 \%$ das partículas.

As massas específicas de cimento e FRG foram determinadas por meio de picnometria a gás hélio, com o equipamento AccuPyc 1330 V2.01, da MicroMetrics. Já a massa específica da areia foi determinada pelo método do frasco de Chapman, de acordo com a NBR NM 53 (ABNT, 2003). As áreas superficiais específicas de cimento e FRG foram determinadas pelo método Blaine de permeabilidade ao ar, por meio da utilização de um analisador superficial automático da marca Acmel, modelo BSA1, e pelo método BET, através do equipamento Gemini VII, da Micromeritics.

As distribuições granulométricas do cimento e dos finos de rocha granítica foram determinadas por granulometria a laser, via seca, em equipamento da marca Microtrac, modelo S3500, disponível no Laboratório de Aplicações de Nanotecnologia em Construção Civil (Nanotec) da Universidade Federal de Santa Catarina (UFSC). Esse ensaio baseia-se na captação da fração de luz que atravessa a amostra em suspensão, analisando a porcentagem de massa acumulada, em função do diâmetro equivalente das partículas, uma vez que as partículas maiores tendem a se depositar mais rapidamente.A distribuição do tamanho de partículas da areia utilizada nesta pesquisa foi determinada de acordo com o procedimento da NBR NM 248 (ABNT, 2003), sendo sua classificação realizada de acordo com a NBR 7211 (ABNT, 2009).

Para a dosagem das argamassas autoadensáveis, foi adotado o método proposto por Repette-Melo (MELO, 2005). Além da argamassa de referência, ou seja, sem FRG, foram dosadas argamassas em que o cimento foi parcialmente substituído pelo FRG, nos teores de 5\%, 15\% e $25 \%$ em volume, visando analisar a influência do acréscimo do teor de substituição nas propriedades das argamassas. Os teores utilizados foram definidos de acordo com análises prévias, em que se verificou que a adição de teores acima de $25 \%$ tornou as argamassas muito secas, aumentando de forma considerável o teor de aditivo superplastificante necessário para garantir a trabalhabilidade adequada. A relação água/cimento foi fixada em 0,46 em todas as argamassas com o intuito de alcançar resistência à compressão superior a $35 \mathrm{MPa}$.

As argamassas foram misturadas utilizando o misturador eletromecânico planetário de bancada da marca Contenco, com duas frequências de rotação $(140 \pm 5 \mathrm{rpm}$ e $285 \pm 5 \mathrm{rpm})$ e capacidade de 5 litros. O tempo 
total de mistura foi de 6 min, segundo o procedimento proposto por Melo (2005), de acordo com a seguinte sequência:

(a) cimento, FRG e $80 \%$ da água em velocidade lenta por $30 \mathrm{~s}$;

(b) adição do agregado miúdo em velocidade lenta por $30 \mathrm{~s}$;

(c) mistura em velocidade rápida por $1 \mathrm{~min}$;

(d) limpeza da pá e descanso da argamassa por 3 min;

(e) incorporação do aditivo e $20 \%$ da água, após 5 min do início da mistura; e

(f) mistura final em velocidade rápida por $1 \mathrm{~min}$.

Já o volume de areia foi mantido constante e igual a $45 \%$ do volume total da argamassa, que está dentro da faixa considerada ideal para argamassas autoadensáveis, que varia entre 40\% e 50\% (MELO, 2005; OKAMURA; OUCHI, 2003; GOMES; GETTU; AGULLÓ, 2003; JIN, 2002; RIZWAN; BIER, 2009; DOMONE, 2006). O volume de areia foi mantido constante com o intuito de avaliar apenas a influência da adição dos finos nas propriedades das argamassas. Em relação ao teor de aditivo superplastificante, foi utilizada a quantidade necessária para que as argamassas autoadensáveis alcançassem um espalhamento entre $240 \mathrm{~mm}$ e $260 \mathrm{~mm}$, considerado o ideal pela Efnarc (2002) e pelos autores do método de dosagem adotado (MELO, 2005).

A Tabela 1 apresenta o consumo dos materiais, em $\mathrm{kg}$, para $1 \mathrm{~m}^{3}$ de argamassa autoadensável para cada dosagem estudada. É possível observar reduções de $2 \%, 7 \%$ e $12 \%$ no consumo de cimento e de água nas misturas com 5\%, 15\% e 25\% de FRG. Em contrapartida, ocorreu o aumento de aditivo superplastificante. As análises econômica e ambiental das argamassas são fundamentais para a verificação de viabilidade da utilização do FRG, contudo não fazem parte do escopo do presente trabalho.

Com o teor de aditivo definido, realizou-se o ensaio do minifunil $\mathrm{V}$ com o intuito de analisar o tempo de escoamento das argamassas com diferentes teores de finos e avaliar, indiretamente, a influência da adição desse material na viscosidade das argamassas. Para a realização dos ensaios de espalhamento e de minifunil V, seguiram-se as diretrizes do Manual Europeu de Práticas Recomendadas, da Efnarc (2002).

Para analisar a influência da incorporação de diferentes teores de FRG na evolução do calor de hidratação, foi realizado o ensaio de calorimetria isotérmica em pastas, contendo os mesmos teores de fino, cimento, água e aditivo superplastificantes das argamassas estudadas. Para isso, foi utilizado um calorímetro isotérmico com quatro canais, da marca Calmetrix, modelo $4000 \mathrm{HPC}$, em uma temperatura de estabilização de $20^{\circ} \mathrm{C}$ durante as primeiras 72 hde hidratação. A mistura das pastas foi feita externamente, seguindo o mesmo procedimento adotado para as argamassas, porém utilizando um misturador elétrico de pequeno porte da marca Mallory.

Os ensaios em estado endurecido foram executados utilizando corpos de prova prismáticos $(40 \mathrm{~mm}$ x $40 \mathrm{~mm}$ x $160 \mathrm{~mm}$ ), sendo moldados 3 corpos de prova para cada idade. Para a moldagem, por se tratar de argamassa autoadensável, não foi realizado nenhum tipo de adensamento. Por fim, a superfície foi regularizada com uma espátula e os corpos de prova, deixados imersos em água saturada com cal até a ruptura.

A resistência à compressão axial, nas idades de 3, 7 e 28 dias, foi determinada de acordo com a NBR 13279 (ABNT, 2005), utilizando a prensa HD-120T da Contenco. Na idade de 28 dias foram realizados, também, o ensaio de absorção de água por capilaridade, de acordo com a NBR 9779 (ABNT, 2012), e o ensaio de porosidade e densidade aparentes, seguindo o princípio de Arquimedes. Por fim, o módulo de elasticidade dinâmico das argamassas foi determinado por meio do equipamento emissor de ondas ultrassônicas da Proceq, modelos PunditLab(+), de acordo com o procedimento descrito na NBR 15630 (ABNT, 2008).

Tabela 1 - Consumo de materiais (kg) para $1 \mathrm{~m}^{3}$ de argamassa autoadensável

\begin{tabular}{c|c|c|c|c|c}
\hline Argamassa & Cimento & FRG & Areia & Água & Aditivo \\
\hline Referência (0\% FRG) & 704,39 & 0,00 & $1.192,05$ & 324,02 & 2,54 \\
5\% FRG & 692,76 & 33,47 & $1.185,11$ & 318,67 & 2,77 \\
15\% FRG & 653,41 & 105,84 & $1.199,49$ & 300,57 & 3,46 \\
25\% FRG & 620,64 & 189,89 & $1.189,45$ & 285,50 & 4,16 \\
\hline
\end{tabular}


De maneira complementar, foi realizada a análise teórica da distância de separação das partículas da pasta constituinte das argamassas estudadas, uma vez que o volume de areia foi mantido constante em todas as formulações. Nessa análise, considera-se também a fração volumétrica de sólidos presentes na mistura e na sua área superficial volumétrica (Equação 1) (CARDOSO, 2009; DAMINELI, 2013; FUNK; DINGER, 1994).

$I P S=\frac{2}{V S A} *\left[\frac{1}{V_{S}}-\frac{1}{1-P_{o f}}\right]$

Onde:

VSA é a área superficial volumétrica $\left(\mathrm{m}^{2} / \mathrm{cm}^{3}\right)$ calculada a partir do produto entre a massa específica do material $\left(\mathrm{g} / \mathrm{cm}^{3}\right)$ e a área superficial específica $\left(\mathrm{m}^{2} / \mathrm{g}\right)$;

Vs é a fração volumétrica de sólidos da mistura; e

$\mathrm{P}_{\text {of }}$ é a fração de poros proveniente da mistura dos materiais finos.

A análise teórica da distância de separação das partículas foi realizada na pasta constituinte das argamassas estudadas, uma vez que o volume de areia foi mantido constante em todas as formulações. A análise da fração de poros foi feita por meio do ensaio de compacidade, por demanda de água, com índice de compactação (K) igual a 6,7. Esse índice representa a energia de compactação associada ao protocolo de adensamento utilizado. Esse ensaio foi realizado com o objetivo de determinar a quantidade de água necessária para preencher todos os espaços vazios da mistura.

Nesse ensaio a água é inserida gradualmente na argamassadeira contendo a mistura de finos até que todos os vazios existentes sejam preenchidos. A partir desse ponto, qualquer quantidade de água adicionada na mistura produz um afastamento entre as partículas, aumentando a fluidez da mistura. Define-se como ponto característico da demanda de água o ponto em que a pasta encontra-se em estado homogêneo e adensado no fundo do recipiente, mostrando que os materiais encontram-se unidos de maneira homogênea ao longo de toda a mistura (SILVA, 2004).

Esse ensaio seguiu o procedimento adaptado de Silva (2004):

(a) pesar uma amostra com aproximadamente $350 \mathrm{~g}$ do material completamente seco;

(b) colocar o material no misturador e adicionar 50\% da água prevista para que seja atingida a demanda de água;

(c) misturar em velocidade baixa por $1 \mathrm{~min}$;

(d) misturar em velocidade baixa e adicionar uma pequena quantidade de água em intervalos de 1 min até visualizar a formação de aglomerados;

(e) deixar a mistura em repouso por 30 s e raspar o recipiente com o auxílio de uma espátula;

(f) misturar em velocidade alta por $1 \mathrm{~min}$; e

(g) finalizar o ensaio quando uma pasta homogênea e adensada se formar no fundo do recipiente.

Foram analisadas, então, quatro composições diferentes para as pastas: $100 \%$ de cimento e sem FRG, como referência, e as pastas com substituição de 5\%, 15\% e 25\% de FRG em relação ao volume de cimento. Após a determinação da quantidade de água correspondente ao estado de demanda de água, a compacidade real pode ser calculada segundo a Equação 2, quando se utiliza apenas um material; e segundo a Equação 3, quando se utilizam dois materiais em conjunto (MOGHADDAM; BAAJ, 2018; SILVA, 2004).

$$
\begin{aligned}
& C=\frac{1}{1+m e * \frac{M_{H 2 O} O}{M_{T}}} \\
& C=\frac{1}{1+\frac{m e 1^{* m e} 2}{\left[m e e^{*} \frac{M_{1}}{M_{T}}+m e_{1} * \frac{M_{2}}{M_{T}}\right]} *\left(\frac{M_{H} 2 O}{M_{T}}\right)}
\end{aligned}
$$

Onde:

me $_{1}$ é a massa específica do material $1\left(\mathrm{~g} / \mathrm{cm}^{3}\right)$;

me $_{2}$ é a massa específica do material $2\left(\mathrm{~g} / \mathrm{cm}^{3}\right)$;

$\mathrm{M}_{1}$ é a massa do material $1(\mathrm{~g})$; 
$\mathrm{M}_{2}$ é a massa do material $2(\mathrm{~g})$;

$\mathrm{M}_{\mathrm{H} 2 \mathrm{O}}$ é a massa de água ao atingir o ponto de saturação $(\mathrm{g})$; e

$\mathrm{M}_{\mathrm{T}}=\mathrm{M}_{1}+\mathrm{M}_{2} \mathrm{e}$ a massa total dos materiais secos (g) (SILVA, 2004).

Com os resultados de compacidade para cada mistura analisada, é possível encontrar a fração de poros $\left(P_{\text {ofg }}\right)$ correspondente à proporção de materiais utilizados por meio da Equação 4.

$P_{o f g}=1-C$

Eq. 4

\section{Resultados e discussões}

\section{Caracterização dos materiais}

Na Tabela 2 são apresentadas as propriedades físicas; e nas Figuras 1 e 2 são exibidas as curvas de distribuição do tamanho de partículas, acumulada e individual respectivamente, dos materiais empregados neste estudo. Observa-se que o FRG utilizado apresenta área superficial Blaine, BET inferior e partículas com maiores diâmetros equivalentes em comparação ao cimento utilizado. Além disso, nota-se que enquanto a distribuição do tamanho de partículas do cimento varia entre $0,6 \mu \mathrm{m}$ e $200 \mu \mathrm{m}$, a do FRG varia apenas entre $12 \mu \mathrm{m}$ e $40 \mu \mathrm{m}$.

\section{Distância de separação das partículas}

A Tabela 3 apresenta os resultados de fração de poros das distribuições granulométricas sem incorporação de FRG (100C-0F) e com incorporação de FRG nos teores de 5\%, 15\% e 25\% (95C-5F, 85C-15F e 75C$25 \mathrm{~F}$, respectivamente). Com os resultados de porosidade obtidos, foi possível calcular a distância de separação das partículas da pasta constituinte das argamassas em estudo.

Como pode ser observado pelos resultados apresentados na Tabela 3, ao aumentar o teor de substituição de cimento por FRG, a porosidade da distribuição diminui. Porém, como a relação água/cimento é mantida constante, com o aumento do teor de FRG na pasta, reduzem-se a quantidade de cimento na mistura e, consequentemente, a quantidade de água presente na mistura.

Tabela 2 - Propriedades físicas das matérias-primas utilizadas

\begin{tabular}{c|c|c|c}
\hline Propriedade & Cimento & FRG & Areia \\
\hline Massa específica $\left(\mathrm{g} / \mathrm{cm}^{3}\right)$ & $3,120 \pm 0,003$ & $2,860 \pm 0,005$ & $2,65 \pm 0,01$ \\
Área superficial Blaine $\left(\mathrm{cm}^{2} / \mathrm{g}\right)$ & $4.099 \pm 52$ & $2.041 \pm 50$ & - \\
Área superficial BET $\left(\mathrm{m}^{2} / \mathrm{g}\right)$ & 1,6417 & 1,2729 & - \\
Mediana do diâmetro equivalente $(\mu \mathrm{m})$ & 15,58 & 16,05 & 379 \\
Dimensão máxima característica $(\mathrm{mm})$ & - & - & 1,18 \\
Módulo de finura & - & - & 1,75 \\
\hline
\end{tabular}

Figura 1 - Curva de distribuição do tamanho de partículas (\% retida acumulada em massa para areia e em volume para cimento e FRG)

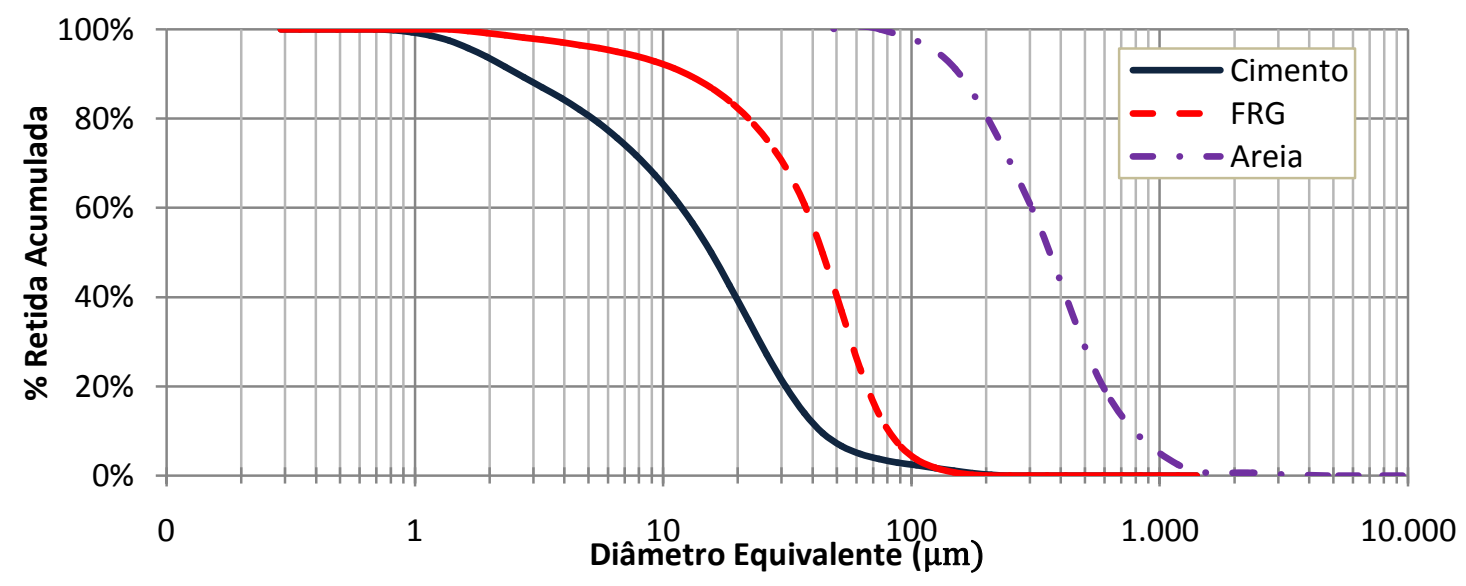


Figura 2 - Curva de distribuição do tamanho de partículas (\% retida individual em massa para areia e em volume para cimento e FRG)

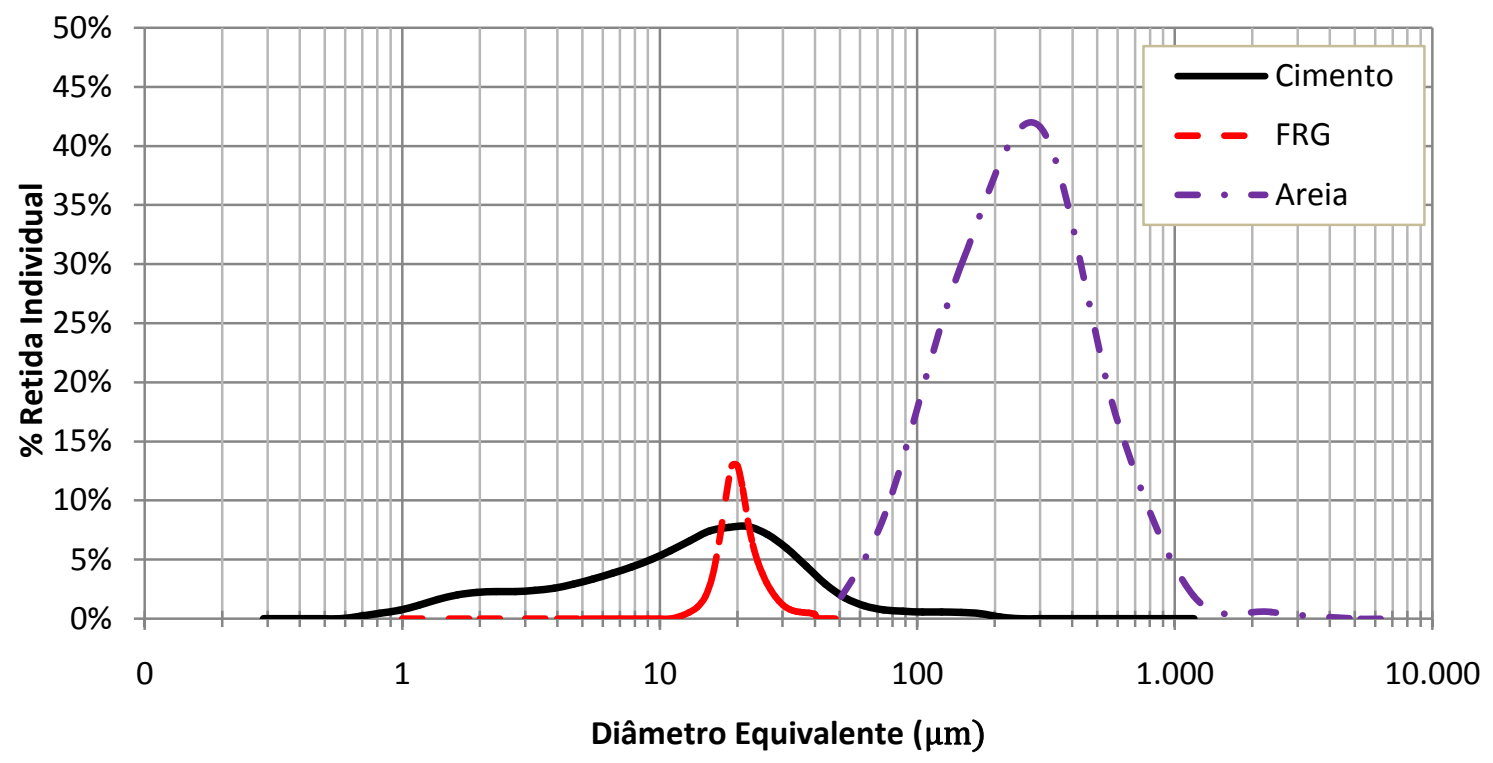

Tabela 3 - Resultados da fração de poros e da distância de separação das partículas das pastas analisadas

Nota: Legenda:

\begin{tabular}{c|c|c|c|c}
\hline Parâmetros & 100C-0F & 95C-5F & 85C-15F & 75C-25F \\
\hline VSA $\left(\mathrm{m}^{2} / \mathrm{cm}^{3}\right)$ & 5,117 & 5,043 & 4,896 & 4,748 \\
VS $(\%)$ & 0,411 & 0,423 & 0,451 & 0,482 \\
$\mathrm{P}_{\text {of }}(\%)$ & 0,477 & 0,472 & 0,456 & 0,454 \\
IPS $(\mu \mathrm{m})$ & 0,203 & 0,186 & 0,155 & 0,102 \\
\hline
\end{tabular}

\footnotetext{
VSA = área superficial volumétrica;

Vs = fração volumétrica de sólidos; e

$P_{\text {of }}=$ fração de poros.
}

Sendo assim, o teor de partículas sólidas (VS) aumenta e, portanto, o IPS reduz, o que pode resultar em aumento de viscosidade (ROJAS-RAMÍREZ et al., 2019), ou seja, com o aumento da incorporação de FRG, obtêm-se distribuição de partículas mais compacta e, consequentemente, menor porosidade para a matriz. Porém, com o aumento do teor de finos, a distância entre partículas diminui, resultando em perda de trabalhabilidade das misturas.

\section{Ensaios em estado fresco}

$\mathrm{Na}$ Figura 3 estão apresentados os teores de aditivo superplastificante empregados para garantir espalhamento médio de $250 \pm 10 \mathrm{~mm}$ para cada teor de FRG utilizado. Como esperado, maiores teores de finos reduzem a fluidez das argamassas, que passam a necessitar de mais aditivo superplastificante para atingir o espalhamento desejado. Esses resultados estão de acordo com os apresentados para a distância de separação das partículas, conforme pode ser observado na Figura 4, em que há forte correlação entre os resultados $\left(\mathrm{R}^{2}=0,9897\right)$. Isso era esperado, já que, com a diminuição do IPS, é necessária uma maior quantidade de aditivo para alcançar amesma consistência, uma vez que as partículas se encontram mais próximas umas das outras.

Os resultados do tempo de escoamento das argamassas, obtidos pelo método do minifunil V, são apresentados na Figura 5. O método Repette-Melo (MELO, 2005) classifica como aceitável as argamassas que possuam tempo de escoamento entre $3,5 \mathrm{~s}$ e $10 \mathrm{~s}$, porém o intervalo considerado ideal é entre $5 \mathrm{~s}$ e $10 \mathrm{~s}$. 
Figura 3 - Teor de aditivo necessário para se atingir espalhamento entre $250 \pm 10 \mathrm{~mm}$ para as argamassas avaliadas em relação aos diferentes teores de FRG

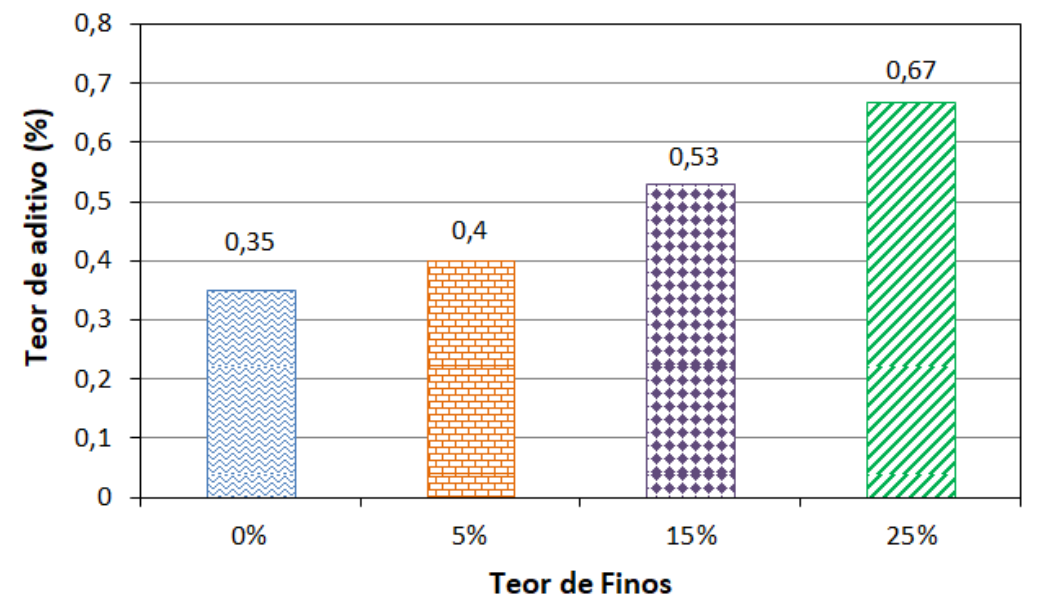

Figura 4 - Correlação entre a distância de separação das partículas e o teor de aditivo superplastificante necessário para se atingir espalhamento entre $250 \pm 10 \mathrm{~mm}$

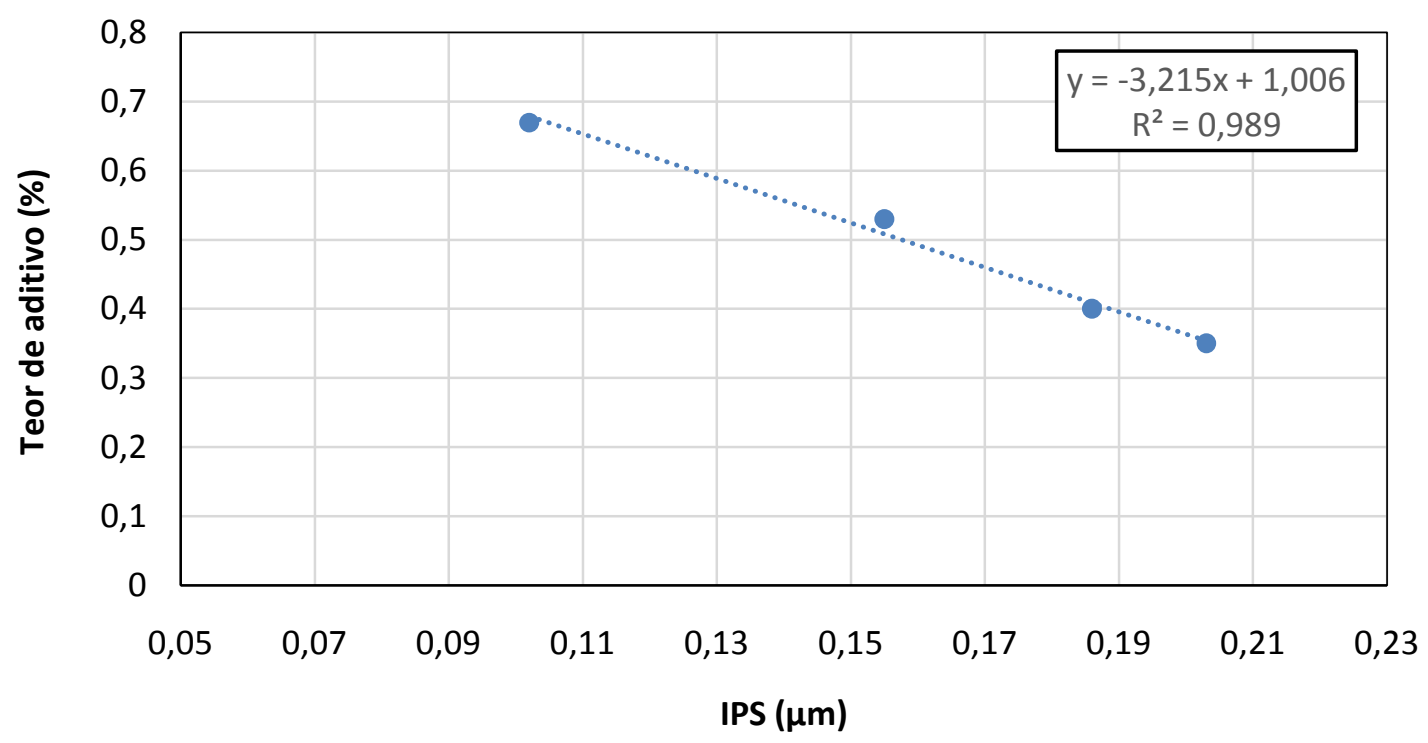

Figura 5 - Tempo de escoamento no minifunil-V das argamassas com diferentes teores de FRG

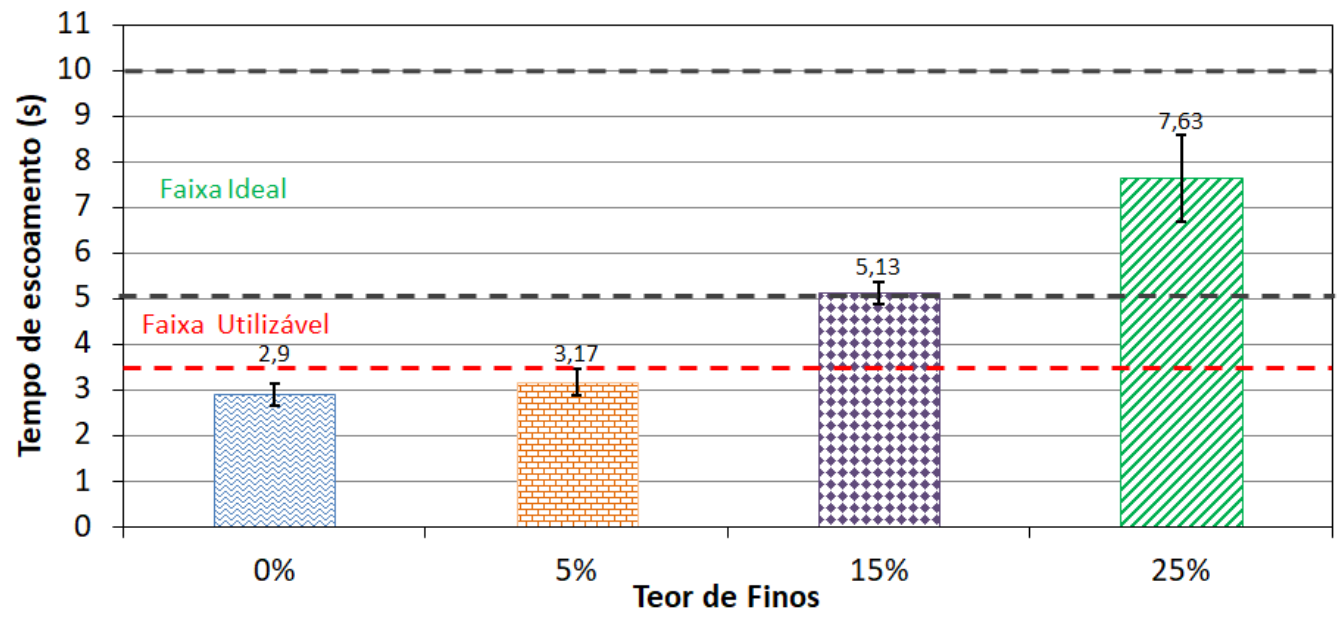


Na Figura 5 nota-se que, com o aumento da quantidade de finos empregada nas misturas, houve um acréscimo do tempo de escoamento das argamassas, mesmo com a elevação do teor de aditivo superplastificante empregado, evidenciando que os finos de rocha granítica atuam como bons modificadores de viscosidade. As argamassas com $15 \%$ e $25 \%$ de finos apresentaram seus respectivos tempos de escoamento dentro da classificação ideal proposta pelo método Repette-Melo (MELO, 2005), enquanto as argamassas de referência e com 5\% de finos apresentaram valores inferiores à faixa considerada utilizável.

Como pode ser observado na Figura 6, existe forte correlação $\left(\mathrm{R}^{2}=0,9881\right)$ entre o tempo de escoamento e a distância entre as partículas. Quanto menor o IPS, maior o tempo de escoamento. Segundo Rojas-Ramírez et al. (2019), ao diminuir a distância entre as partículas, a sua mobilidade é reduzida devido ao aumento das forças internas de fricção. Assim, o escoamento é afetado e tem-se um aumento na viscosidade (ROJASRAMÍREZ et al., 2019).

É possível observar que, apesar de apresentarem valores de espalhamento dentro da faixa estabelecida $250 \pm 10 \mathrm{~mm}$, as argamassas autoadensáveis com adição de FRG mostraram maiores tempos de escoamento no minifunil V. Isso evidencia que a adição de FRG, com maior teor de aditivo superplastificante, é capaz de corrigir a viscosidade da argamassa sem afetar o seu espalhamento.

Contudo, é importante destacar que esses ensaios apresentam apenas uma tendência de comportamento em relação à viscosidade, pelo fato de serem unidirecionais (minifunil $\mathrm{V}$ ) e bidirecionais (mini-slump test) e sem obstáculos, o que não representa todas as situações encontradas na prática, durante a construção.

\section{Calorimetria isotérmica}

Nas Figuras 7a e 7b são apresentadas as curvas de taxa de calor liberado e de calor acumulado respetivamente, normalizadas pela massa de pasta ensaiada. Já nas Figuras 7 c e $7 \mathrm{~d}$ são exibidas as curvas de taxa de calor liberado e de calor acumulado, respetivamente, normalizadas pela massa de cimento. $\mathrm{Na}$ Tabela 4 são mostradas algumas propriedades obtidas a partir da análise dessas curvas.

Na curva de taxa de liberação de calor (Figuras7a e 7c) são observados os cinco estágios da hidratação: I pré-indução, II - indução, III - aceleração, IV - desaceleração e V - reações finais. No período de desaceleração é percebidoum pico de liberação de calor, referente à depleção de sulfatos (DS), momento em que ocorre a exaustão de sulfatos na solução e é retomada a reação dos aluminatos (BULLARD et al., 2011).

Observando as Figuras 7a e 7b, que ilustram a taxa de calor máxima e o calor acumulado normalizados pela massa de pasta (Tabela 4), é possível perceber uma redução no calor liberado durante a hidratação ao substituir cimento por FRG. Esse resultado era esperado devido à redução no teor de cimento. Menor liberação de calor reduz a probabilidade de fissuração por secagem e a formação de etringita tardia (ZHANG et al., 2018).

Figura 6 - Correlação entre a distância de separação das partículas e o tempo de escoamento no minifunil-V

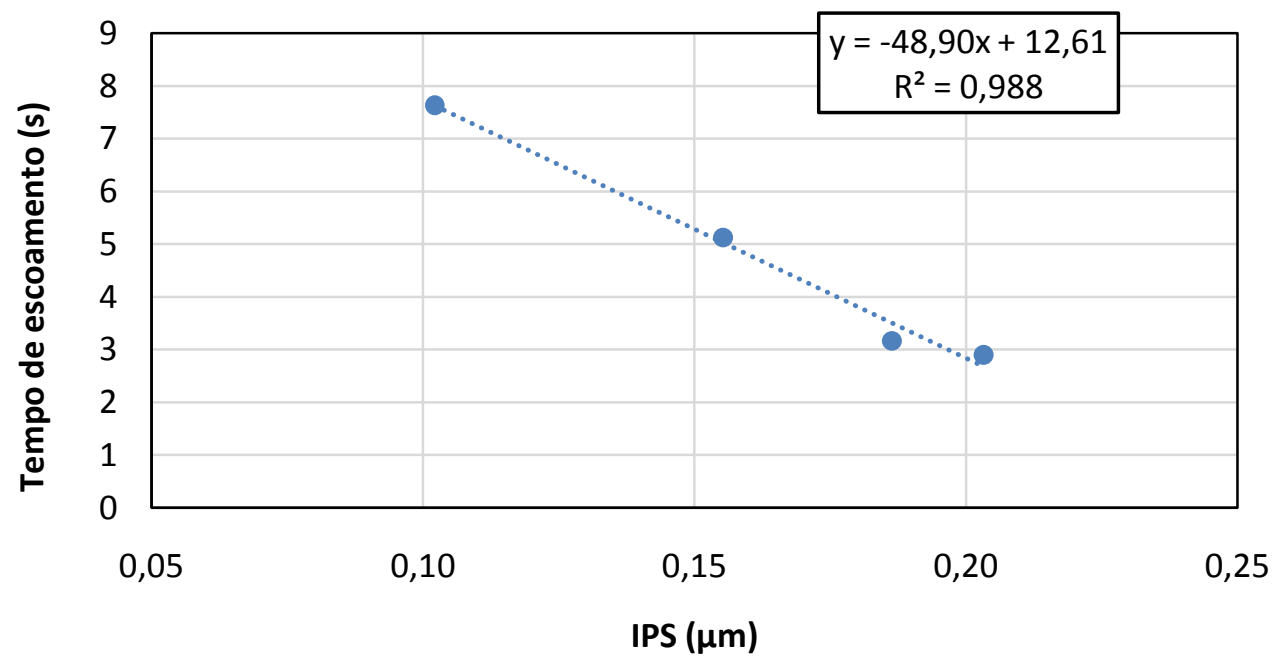


Figura 7 - Curvas de taxa de calor liberado e acumulado durante as primeiras $48 \mathrm{~h}$, normalizadas por grama (A e B) de pasta e por grama (C e D) de cimento, respectivamente

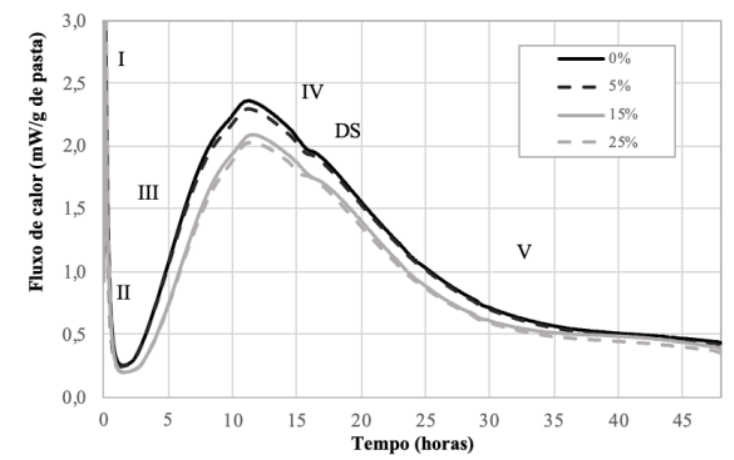

(a)

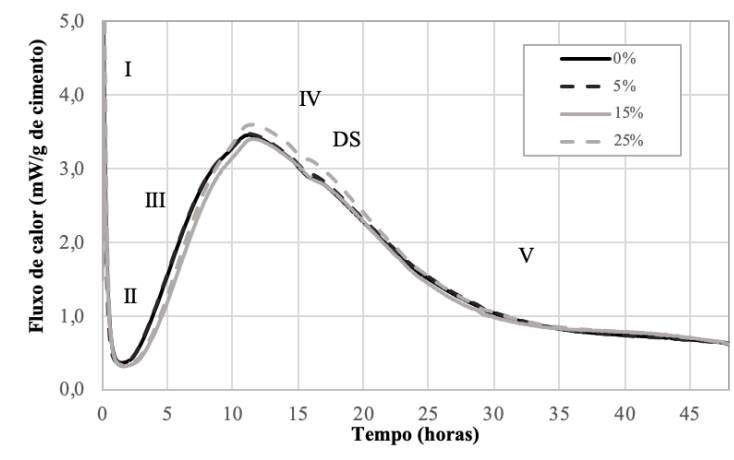

(c)

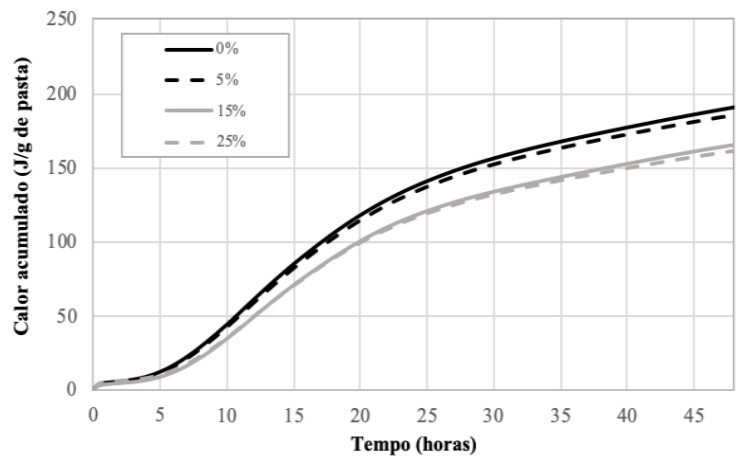

(b)

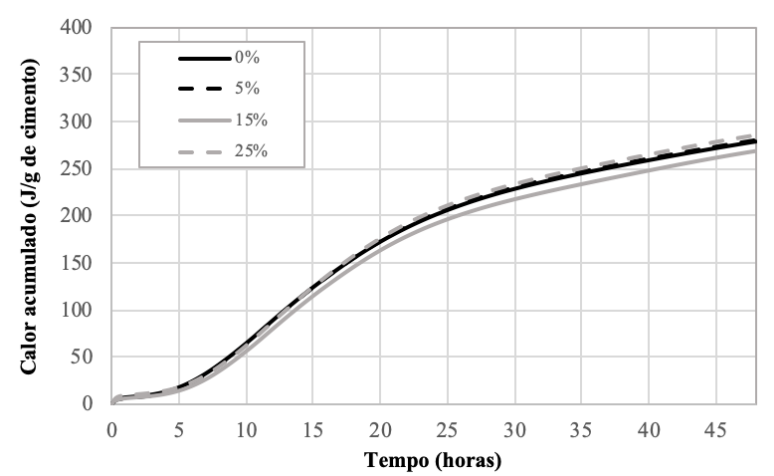

(d)

Tabela 4 - Pontos característicos da curva de calorimetria para as pastas contendo diferentes teores de FRG

\begin{tabular}{c|c|c|c|c}
\hline Pontos característicos da curva de calorimetria & $\mathbf{1 0 0 C - 0 F}$ & $\mathbf{9 5 C - 5 F}$ & $\mathbf{8 5 C - 1 5 F}$ & $\mathbf{7 5 C - 2 5 F}$ \\
\hline Período de indução $(\mathrm{h})$ & 1,43 & 1,62 & 2,10 & 2,17 \\
Tempo para o pico máximo de liberação de calor $(\mathrm{h})$ & 11,32 & 11,20 & 11,58 & 11,47 \\
Tempo no qual ocorre a depleção de sulfatos $(\mathrm{h})$ & 16,38 & 16,33 & 16,72 & 16,05 \\
Taxa de liberação de calor máxima (mW/g de pasta) & 2,36 & 2,30 & 2,09 & 2,03 \\
Taxa de liberação de calor máxima (mW/g de cimento) & 3,46 & 3,48 & 3,41 & 3,60 \\
Calor total liberado após 48 h (J/g de pasta) & 190,62 & 185,46 & 165,24 & 161,21 \\
Calor total liberado após 48 h (J/g de cimento) & 279,00 & 280,47 & 268,90 & 285,78 \\
\hline
\end{tabular}

Contudo, ao observar as curvas (Figuras 7c e 7d), com a taxa de calor máxima e de calor acumulado, normalizadas pela massa de cimento (Tabela 4), não se notam diferenças significativas entre as amostras. A utilização de materiais cimentícios suplementares, tais como metacaulim, sílica ativa e fíler calcário, geralmente resulta na intensificação das reações de hidratação do cimento, devido ao maior espaço disponível para o crescimento dos produtos de hidratação e à nucleação heterogênea (SCRIVENER et al., 2015). Esse comportamento não é observado ao se substituir cimento por FRG, devido ao tamanho das partículas do resíduo, que, conforme exibido na Tabela 4 e nas Figuras 1 e 2, apresenta área superficial menor e diâmetros equivalentes maiores do que as partículas de cimento.

Observando as Figuras 7a e 7c, e como indicado na Tabela 4, ao aumentar o teor de FRG, o período de indução (II) se estende, indicando, assim, retardo nas reações de hidratação. Esse comportamento pode ser explicado pelo progressivo acréscimo no teor de aditivo superplastificante, à base de policarboxilato, ao se incorporar o FRG, como indicado na Figura 3. Esse tipo de aditivo é conhecido por retardar a hidratação do cimento (KONG et al., 2016). Os grupos carboxílicos do aditivo, carregados negativamente, são adsorvidos nas partículas de cimento, carregadas positivamente, o que fornece a dispersão dessas. Contudo, essas cadeias dificultam a dissolução da alita e do $\mathrm{C}_{3} \mathrm{~A}$, seja pelo próprio mecanismo de adsorção, seja pelo consumo de íons $\mathrm{Ca}^{2+}$ da solução, o que retarda a hidratação do cimento (JANSEN et al., 2012). 
Por fim, é possível observar que em todas as curvas de taxa de calor liberado (Figura 7a) a curva associada à depleção de sulfatos e à consequente retomada das reações dos aluminatos se encontra após o pico principal de hidratação da alita, indicando, assim, que os cimentos estão com teores adequados de sulfato de cálcio. Analisando os tempos para depleção de sulfatos indicados na Tabela 4, não é possível observar uma tendência ao se incorporar o FRG, sendo as diferenças observadas de apenas alguns minutos. Dessa forma, é possível afirmar que a presença de FRG pouco ou nada impacta no teor ótimo de sulfatos.

\section{Ensaios em estado endurecido}

Ao analisar os resultados de porosidade e densidade aparentes (Figura 8), observam-se uma redução da porosidade (Figura 8a) e um acréscimo da densidade (Figura 8b) com o aumento do teor de FRG. Assim, pode-se concluir, novamente, que o aumento da incorporação de FRG tende a reduzir a quantidade de poros da mistura, elevando a densidade dessa, como visto pela redução do $\mathrm{P}_{\text {of }}$ apresentada na Tabela 3 .

Como consequência da elevação da densidade, a velocidade do pulso ultrassônico através da argamassa aumenta, isto é, há um acréscimo do módulo de elasticidade dinâmico, conforme apresentado na Figura 9. O comportamento observado pode ser atribuído à melhor distribuição granulométrica da pasta, ao elevar o teor de substituição do cimento por FRG, evidenciada pelo menor IPS (Tabela 3), reduzindo a quantidade de vazios presentes e, consequentemente, a porosidade aparente, o que aumenta o módulo de elasticidade dinâmico da argamassa.

Figura 8 - Porosidade (a) e densidade (b) aparentes das argamassas com diferentes teores de FRG

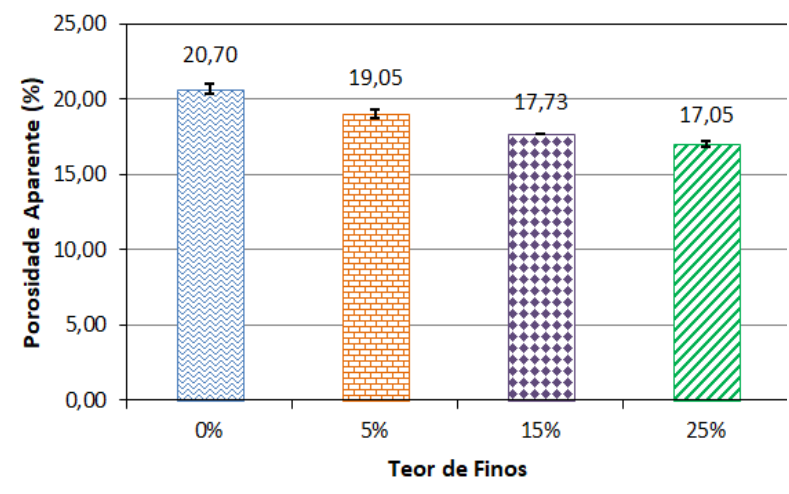

(a)

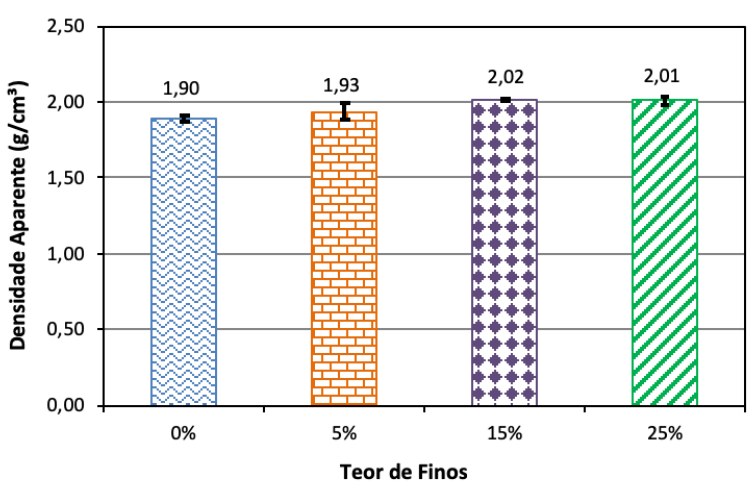

(b)

Figura 9 - Módulo de elasticidade dinâmico das argamassas com diferentes teores de FRG

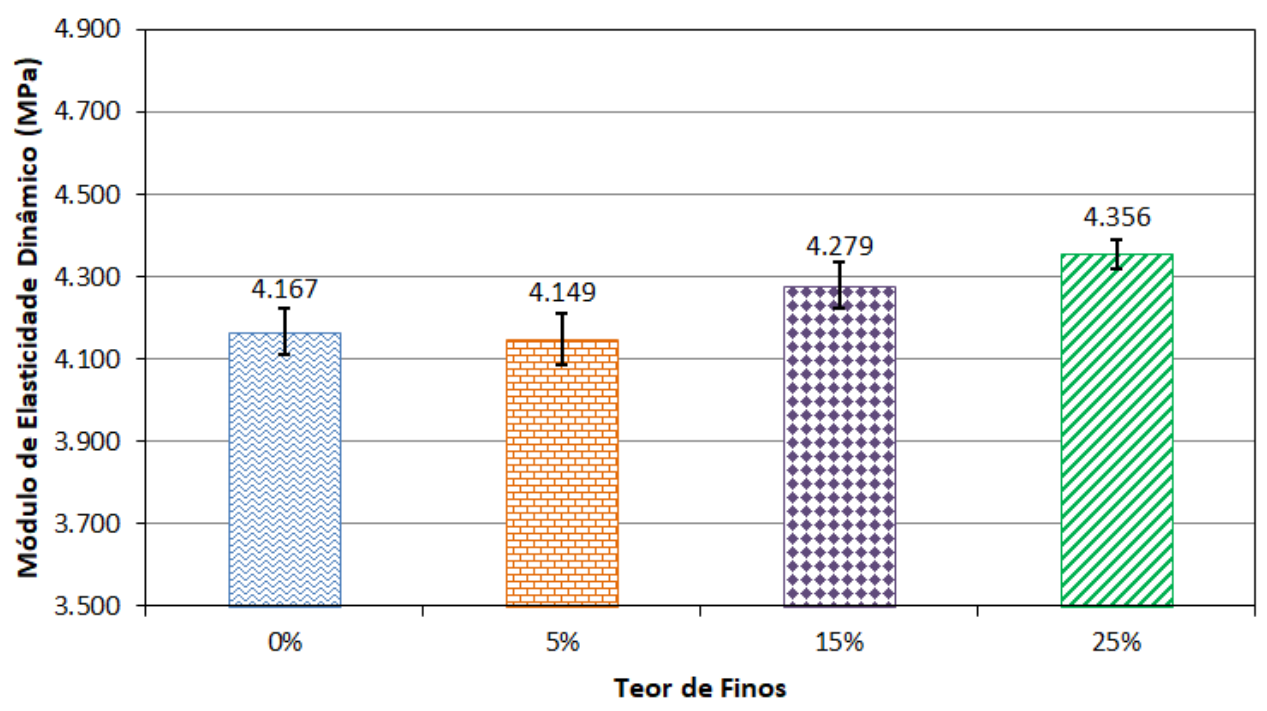


A Figura 10 apresenta os resultados da resistência à compressão das argamassas nas idades de 3, 7 e 28 dias das diferentes formulações. Ressalta-se que os resultados aqui discutidos representam uma tendência do que é esperado que ocorra em obras reais, uma vez que foram analisados apenas 3corpos de prova para cada ensaio. É possível observar que, em todas as idades avaliadas, a incorporação dos finos, apesar de reduzir o consumo de cimento em $2 \%, 5 \%$ e $12 \%$ (Tabela 1) e a liberação de calor, tende a não prejudicar a resistência à compressão axial das argamassas. Nota-se que a argamassa com 15\% de FRG apresentou as maiores resistências, possivelmente devido ao empacotamento mais eficiente das partículas.

Esses resultados estão de acordo com aqueles encontrados para a análise da densidade aparente das misturas, uma vez que a formulação com incorporação de $15 \%$ de FRG apresenta a maior densidade aparente e, consequentemente, a maior resistência à compressão.

A partir da análise dos resultados dos coeficientes de absorção de água por capilaridade (Figura 11), é possível concluir que a adição de FRG não afetou de maneira significativa essa importante propriedade. Isso provavelmente ocorre devido à ação conjunta do melhor empacotamento de partículas, que tende a reduzir a porosidade, com o refinamento dos poros resultante da adição dos finos, a qual costuma aumentar a absorção capilar. Esse resultado é relevante no que tange à durabilidade dos materiais, uma vez que a entrada de agentes agressivos no interior do concreto se dá, principalmente, pela absorção capilar. Assim, tem-se um indicativo de que a adição de finos não é prejudicial à durabilidade das argamassas.

Figura 10 - Resistência à compressão axial das argamassas com diferentes teores de FRG

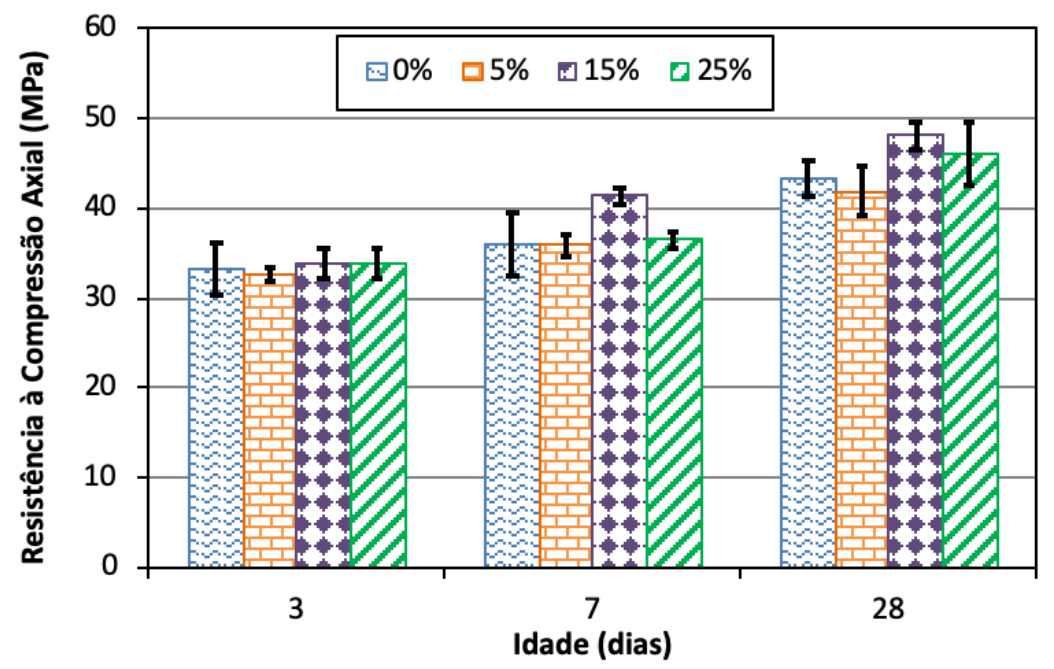

Figura 11 - Coeficiente de absorção de água por capilaridade das argamassas com diferentes teores de FRG

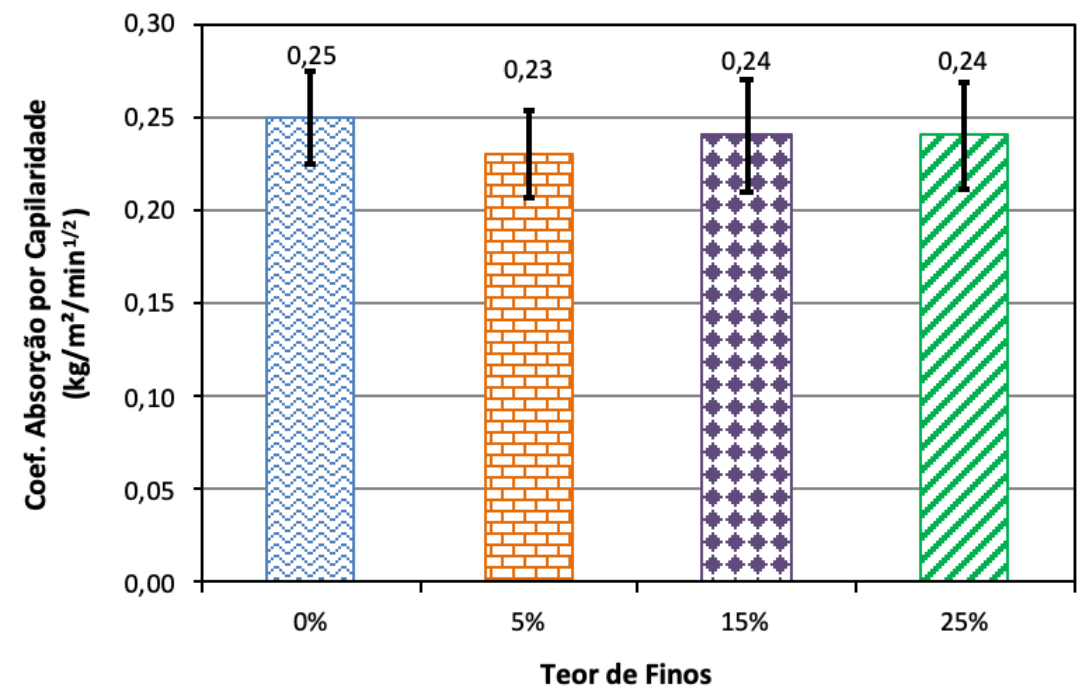

462 Siqueira, T. P. L.; Andrade Neto, J. da S.; Dias, C. M. R.; Ribeiro, D. V. 


\section{Conclusões}

A partir da análise dos dados obtidos, pode-se concluir que a adição de finos de rocha granítica reduz de forma significativa a porosidade das misturas e, por manter a relação água/cimento constante, essa incorporação reduz a distância entre partículas na pasta. Conclui-se que essa redução do IPS resulta em perda da trabalhabilidade das misturas, levando à necessidade de maior teor de aditivo para alcançar o mesmo espalhamento.

Pode-se observar que o aumento do teor de FRG na mistura eleva de maneira significativa o tempo de escoamento das argamassas autoadensáveis, tendo a adição de $15 \%$ e $25 \%$ de finos proporcionado viscosidade ideal nas argamassas, de acordo com o método de dosagem proposto por Repette-Melo, o que também pode ser justificado pela redução do espaçamento entre partículas proporcionada pela incorporação dos finos.

Em relação à calorimetria, as pastas com FRG liberaram uma quantidade inferior de calor devido ao menor teor de cimento. Contudo, essa adição não alterou a taxa de hidratação das partículas de cimento nem o teor ótimo de sulfatos. Por fim, o maior teor de aditivo superplastificante nas misturas com FRG foi responsável por prolongar o período de indução.

Além disso, percebe-se uma redução na porosidade aparente das argamassas autoadensáveis com o aumento do teor de FRG empregado. Essa redução da porosidade resultou no acréscimo da velocidade do pulso ultrassônico através da argamassa, aumentando o módulo de elasticidade dinâmico. Essa redução da porosidade está diretamente relacionada com a distribuição granulométrica otimizada pela adição de FRG. De maneira similar, conclui-se que, com o aumento do teor de FRG, tem-se um aumento da densidade aparente das argamassas autoadensáveis.

Verificou-se que a substituição parcial do cimento pelo FRG não promoveu redução de resistência à compressão devido à supressão de material cimentício das argamassas, havendo um aumento significativo da resistência aos 28 dias com 15\% de substituição de cimento por FRG. Ao analisar os resultados de coeficiente de absorção capilar, conclui-se que a adição de finos de rocha não modifica significativamente a absorção de água por capilaridade. Ressalta-se a importância da realização de novos estudos com maior quantidade de análises, de forma a obter análise estatística mais significativa e permitir que os resultados aqui encontrados sejam reproduzidos em obras reais.

Sendo assim, pode-se concluir que os finos de rocha granítica analisados na pesquisa podem ser considerados bons modificadores de viscosidade, resultando em argamassas autoadensáveis com reologia adequada, sem a necessidade de utilização de aditivos modificadores de viscosidade, além de não prejudicar o desempenho mecânico das argamassas. Contudo, para verificar a viabilidade econômica de tal substituição, faz-se necessário um estudo econômico detalhado, considerando os custos de coleta, transporte, armazenamento e beneficiamento (separação granulométrica) desse material e dos aditivos superplastificantes e modificadores de viscosidade. Destaca-se, ainda, a necessidade de estudos que analisem a eventual redução dos impactos ambientais decorrentes da utilização dos FRG.

\section{Referências}

ABDOLLAHNEJAD, Z. et al. Comparative Study on the effects of recycled glass-fiber on drying shrinkage rate and mechanical properties of the self-compacting mortar and fly ash-slag geopolymer mortar. Journal of Materials in Civil Engineering, v. 29, n. 8, p. 04017076, 2017.

ALMEIDA, S. L. M.; SAMPAIO, J. A. Obtenção de areia artificial com base em finos de pedreira. In: ENCONTRO NACIONAL DE TRATAMENTO DE MINÉRIOS E METALURGIA EXTRATIVA, 19. Recife, 2002. Anais [...] Recife, 2002.

AMERICAN SOCIETY FOR TESTING AND MATERIALS. C-780: standard test method for preconstruction and construction evaluation of mortars for plain and reinforced unit masonry. Philadelphia, 1991.

ASSOCIAÇÃO BRASILEIRA DE NORMAS TÉCNICAS. NBR 9779: argamassa e concreto endurecidos: determinação da absorção de água por capilaridade. Rio de Janeiro, 2012.

ASSOCIAÇÃO BRASILEIRA DE NORMAS TÉCNICAS. NBR 13279: argamassa para assentamento e revestimento de paredes e tetos: determinação da resistência à tração na flexão e à compressão. Rio de Janeiro, 2005. 
ASSOCIAÇÃO BRASILEIRA DE NORMAS TÉCNICAS. NBR 6461: blocos cerâmicos para alvenaria: verificação da resistência à compressão. Rio de Janeiro, 1983a.

ASSOCIAÇÃO BRASILEIRA DE NORMAS TÉCNICAS. NBR 7211: agregado para concreto: especificação. Rio de Janeiro, 1983b.

ASSOCIAÇÃO BRASILEIRA DE NORMAS TÉCNICAS. NBR 7211: agregados para concreto: especificação. Rio de Janeiro, 2009.

ASSOCIAÇÃO BRASILEIRA DE NORMAS TÉCNICAS. NBR NM 248: agregados: determinação da composição granulométrica. Rio de Janeiro, 2003.

BARROS, M. M. B. Metodologia para implantação de tecnologias construtivas racionalizadas na produção de edifícios. São Paulo, 1996. 410 f. Tese (Doutorado em Engenharia Civil) - Escola Politécnica, Universidade de São Paulo, São Paulo, 1996.

BENLI, A.; KARATAŞ, M.; BAKIR, Y. An experimental study of different curing regimes on the mechanical properties and sorptivity of self-compacting mortars with fly ash and silica fume. Construction and Building Materials, v. 144, p. 552-562, 2017.

BLEDZIK, A. K. et al. A comparison of compounding process and wood type for wood fibre-pp composites. Composites Part A: Applied Science and Manufacturing, v. 36, p. 789-797, 2005.

BRANDÃO, D. Q.; HEINECK, L. F. M. Classificação das formas de aplicação da flexibilidade arquitetônica planejada em projetos de edifícios residenciais. In: ENCONTRO NACIONAL DE TECNOLOGIA DO AMBIENTE CONSTRUÍDO, 7., Florianópolis, 1998. Anais [...] Florianópolis: UFSC, ANTAC, 1998.

CARDOSO, F. A. Método de formulação de argamassas de revestimento baseado em distribuição granulométrica e comportamento reológico. São Paulo, 2009, 158 f. Tese (Doutorado em Engenharia de Construção Civil) - Escola Politécnica da Universidade de São Paulo, São Paulo, 2009.

D’AGOSTINO, L. Z.; SOARES, L. O uso de finos de pedreira de rocha granítico-gnáissica em substituição às areias naturais na elaboração de argamassa. Geociências, São Paulo, v. 22, p.65-73, 2003.

DAMINELI, B. L. Conceitos para formulação de concretos com baixo consumo de ligantes: controle reológico, empacotamento e dispersão de partículas. São Paulo, 2013. 265 f. Tese (Doutorado em Engenharia) - Escola Politécnica da Universidade de São Paulo, São Paulo, 2013.

DOMONE, P. L. Self-compacting concrete: an analysis of 11 years of case studies. Cement and Concrete Composites, v. 28, n. 2, p. 197-208, 2006.

ELMOATY, A. E. M. A. Mechanical properties and corrosion resistance of concrete modified with granite dust. Construction and Building Materials, v. 47, p. 743-752, 2013.

ELYAMANY, H. E.; ELMOATY, A. E. B. A.; MOHAMED, B. Effect of filler types on physical, mechanical and microstructure of self compacting concrete and Flow-able concrete. Alexandria Engineering Journal, v. 53, p. 295-307, 2014.

EXPERTS FOR SPECIALISED CONSTRUCTION AND CONCRETE SYSTEMS. Specifications and guidelines for self-compacting concrete. Inglaterra, 2002.

FELEKOGLU, B. Utilisation of high volumes of limestone quarry wastes in concrete industry (selfcompacting concrete case). Resources, Conservation and Recycling, v. 51, n. 4, p. 770-791, 2007.

FUNK, J. E.; DINGER, D. R. Predictive process control of crowded particulate suspensions applied to ceramic manufacturing. New York: Springer Science+Business Media, 1994.

GOMES, P. C. C.; GETTU, R.; AGULLÓ, L. Uma nova metodologia para obtenção de concreto autoadensável de alta resistência com aditivos minerais. In: SIMPÓSIO EPUSP SOBRE ESTRUTURAS DE CONCRETO, 5., São Paulo, 2003. Anais [...] São Paulo, 2003.

HO, D.W. S. et al. The use of quarry dust for SCC applications. Cement and Concrete Research, v. 32, n. 4, p. 505-511, 2002.

JANSEN, D. et al. Change in reaction kinetics of a Portland cement caused by a superplasticizer: calculation of heat flow curves from XRD data. Cement and Concrete Research, v. 42, p. 327-332, 2012. 
JIN, J. Properties of mortar for self-compacting concrete. Londres, 2002. 398 f. Tese (Doutorado em Engenharia Civil) - University ofLondon, London, 2002.

KONG, F. et al. Effects of polycarboxylate superplasticizers with different molecular structure on the hydration behavior of cement paste. Construction and Building Materials, v. 105, p. 545-553, 2016.

LAVELLE, J. A. Acrylic latex-lodified Portland cement. ACI Materials Journal, Detroit, v. 6, n. 1, p. 4148, jan. 1988.

LI, L. G. et al. Filler technology of adding granite dust to reduce cement content and increase strength of mortar. Powder Technology, v. 342, p. 388-396, 2019.

MACIEL, M. H. et al. Efeito da variação do consumo de cimento em argamassas de revestimento produzidas com base nos conceitos de mobilidade e empacotamento de partículas. Ambiente Construído, Porto Alegre, v. 18, n. 1, p. 245-259, jan./mar. 2018.

MELO, K. A. Contribuição à dosagem de concreto auto-adensável com adição de fíler calcário. Florianópolis, 2005. 183 f. Dissertação (Mestrado em Engenharia Civil) - Universidade Federal de Santa Catarina, Florianópolis, 2005.

MOGHADDAM, T. B.; BAAJ, H. Application of compressible packing model for optimization of asphalt concrete mix design. Construction and Building Materials, v. 159, p. 530-539, 2018.

OKAMURA, H.; OUCHI, M. Self-compacting concrete. Journal of advanced concrete technology, v. 1, n. 1, p. 5-15, 2003.

RAPOPORT, A. Environmental cognition in cross-cultural perspective. In: MOORE, G. T.; GOLLEDGE, R. G. (ed.). Environmental Knowing. Stroudsburg: Dowden, Hutchinson and Ross, 1976.

RIZWAN, S. A.; BIER, T. A. Self-consolidating mortars using various secondary raw materials. ACI Materials Journal, v. 106, n. 1, p. 25-32, 2009.

RODRIGUES, G. L.; MANTOVANI, L. E.; LOPES, K. Um estudo da poeira respirável de basalto, na produção de brita, e sua influência para o sistema respiratório do trabalhador. In: ENCONTRO NACIONAL DE ENGENHARIA DE PRODUÇÃO, 24., Florianópolis, 2004. Anais [...] Florianópolis, 2004.

ROJAS-RAMÍREZ, R. A. et al. The impact of vermiculite residual fines in the rheological properties of cement pastes formulated with different waste contents. Applied Clay Science, v. 170, p. 97-105, 2019.

SADEK, D. M.; EL-ATTAR, M. M.; ALI, H. A. Reusing of marble and granite powders in self-compacting concrete for sustainable development. Journal of Cleaner Production, v. 121, p. 19-32, 2016.

ŞAHMARAN, M.; CHRISTIANTO, H. A.; YAMAN, I. O. The effect of chemical admixtures and mineral additives on the properties of self-compacting mortars. Cement and Concrete Composites, v. 28, n. 5, p. 432-440, 2006.

SCRIVENER, K. L.; JUILLAND, P.; MONTEIRO, P. J. M. Advances in understanding hydration of Portland cement. Cement and Concrete Research, v. 78, p. 38-56, 2015.

SILVA, A. S. M. Dosagem de concreto pelos métodos de empacotamento compressível e aïtcin-faury modificado. Rio de Janeiro, 2004, 152 f. Dissertação (Mestrado em Engenharia Civil) - Escola de Engenharia, Universidade Federal do Rio de Janeiro, Rio de Janeiro, 2004.

VARHEN, C. et al. Effect of the substitution of cement by limestone filler on the rheological behaviour and shrinkage of microconcretes. Construction and Building Materials, v. 125, p. 375-386, 2016.

ZHANG, H. et al. A starch-based admixture for reduction of hydration heat in cement composites.

Construction and Building Materials, v. 173, p. 317-322, 2018.

\section{Agradecimentos}

Os autores agradecem à Capes e ao CNPq pelas bolsas fornecidas durante o período da realização desta pesquisa, bem como pelos recursos para a aquisição dos equipamentos utilizados; ao Programa de PósGraduação em Engenharia Civil (PPEC/UFBA), ao Centro Tecnológico da Argamassa (Ceta/UFBA), especialmente ao técnico Paulo Santana pelo apoio na realização das atividades; e ao Laboratório de Ensaios em Durabilidade dos Materiais (LEDMa/UFBA) pela infraestrutura e pelos equipamentos empregados neste trabalho. 
Thaís Pinto Lôbo Siqueira

Departamento de Ciência e Tecnologia dos Materiais, Escola Politécnica | Universidade Federal da Bahia | Rua Aristides Novis, 2, $3^{\circ}$ andar, Federação | Salvador - BA - Brasil | CEP 40210-630 | Tel.: (71)99334-5335 | E-mail: thaisplsiqueira@gmail.com

\section{José da Silva Andrade Neto}

Departamento de Ciência e Tecnologia dos Materiais, Escola Politécnica | Universidade Federal da Bahia | Tel.: (71) 99602-8008 | E-mail: josedasilvaandradeneto@gmail.com

\section{Cleber Marcos Ribeiro Dias}

Departamento de Ciência e Tecnologia dos Materiais, Escola Politécnica | Universidade Federal da Bahia | Tel.: (71) 98825-8688 | E-mail: clebermrd@gmail.com

\section{Daniel Véras Ribeiro}

Departamento de Ciência e Tecnologia dos Materiais, Escola Politécnica | Universidade Federal da Bahia | Tel.: (71) 3283-9852 | E-mail: verasribeiro@hotmail.com

\section{Ambiente Construído}

Revista da Associação Nacional de Tecnologia do Ambiente Construído

Av. Osvaldo Aranha, $99-3^{\circ}$ andar, Centro

Porto Alegre - RS - Brasil

$$
\text { CEP } 90035-190
$$

Telefone: +55 (51) 3308-4084

Fax: +55 (51) 3308-4054

www.seer.ufrgs.br/ambienteconstruido

E-mail: ambienteconstruido@ufrgs.br

This is an open-access article distributed under the terms of the Creative Commons Attribution License. 